\title{
Adolescent pregnancy: an overview
}

\section{Seetesh Ghose*, Lopamudra B. John}

Department of Obstetrics and Gynecology, Mahatma Gandhi Medical College and Research Institute, Puducherry, India

Received: 11 August 2017

Accepted: 09 September 2017

\section{*Correspondence:}

Dr. Seetesh Ghose,

E-mail: seetesh@mgmcri.ac.in

Copyright: () the author(s), publisher and licensee Medip Academy. This is an open-access article distributed under the terms of the Creative Commons Attribution Non-Commercial License, which permits unrestricted non-commercial use, distribution, and reproduction in any medium, provided the original work is properly cited.

\begin{abstract}
A pregnancy can take place at any time before or after puberty. Adolescent pregnancy is defined as pregnancy under the age of 20 years. It is a problem in both developed and developing country. It raises various human right issues i.e. an adolescent pregnant girl is forced to leave school, depriving her right to education; she is prevented from using any contraception or reproductive health related information, so she is also denied her right to health. As many adolescents are neither physically nor psychologically ready for pregnancy or childbirth, this reproductive event makes them more vulnerable to complications resulting in devastating health consequences for them. Early drop out from the school and health problem jeopardize their income-earning potential.
\end{abstract}

Keywords: Adolescence, Complications, Pregnancy

\section{INTRODUCTION}

A pregnancy can take place at any time before or after puberty. Adolescent pregnancy is defined as pregnancy under the age of 20 years. It is a problem in both developed and developing country.

It raises various human right issues i.e. an adolescent pregnant girl is forced to leave school, depriving her right to education, she is also prevented from using any contraception or reproductive health related information hence she is also denied her right to health.

As many adolescents are neither physically nor psychologically ready for pregnancy or childbirth, this reproductive event makes them more vulnerable to complications resulting in devastating health consequences for them. Early drop out from the school and health problems jeopardize their income-earning potential.

\section{Global scenario}

Worldwide $11 \%$ of all births occur during adolescent age. This includes approximately 16 million girls aged 15 to 19 years and two million girls under the age of 15.95 per cent of the world's birth to adolescents (girls aged 15-19) takes place in low and middle-income countries. ${ }^{1}$ Tens of thousands of adolescents die annually due to causes related to pregnancy and childbirth. These are the second most leading cause of death among the adolescent girls, aged 15-19, globally. ${ }^{3}$ According to UNFPA [2010], India (20 percent) and China (16 percent) together account for more than one-third of the global total. In India adolescent fertility rate is 23 . The global adolescent fertility rates (2015) are given in Figure 1, Figure 2, Figure 3.

\section{Indian scenario}

UNFPA predicted "India will retain the biggest national adolescent girl population, with hardly any net change 
from 2010 to 2030 (93 million to 95 million). ${ }^{4}$ Adolescent pregnancy in India is high with 62 pregnant teens out of every 1,000 women. ${ }^{5}$ It was observed from UNFPA report released on 2013, with $11,875,182$ pregnancies, India topped the chart of 10 countries with the greatest numbers of women aged between 20 and 24 who gave birth before their age 18 . UN also said every year some four million teenage girls in India have babies. $^{4}$

\section{1-50}

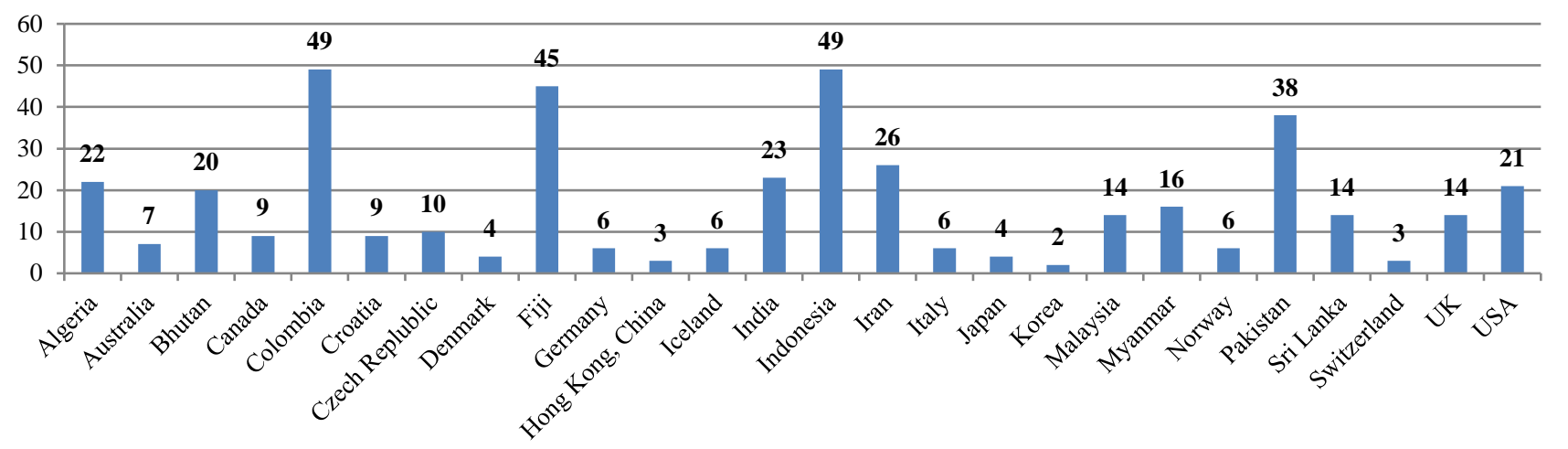

Figure 1: Global adolescent fertility rate (births per 1,000 women ages 15-19) (1-50).

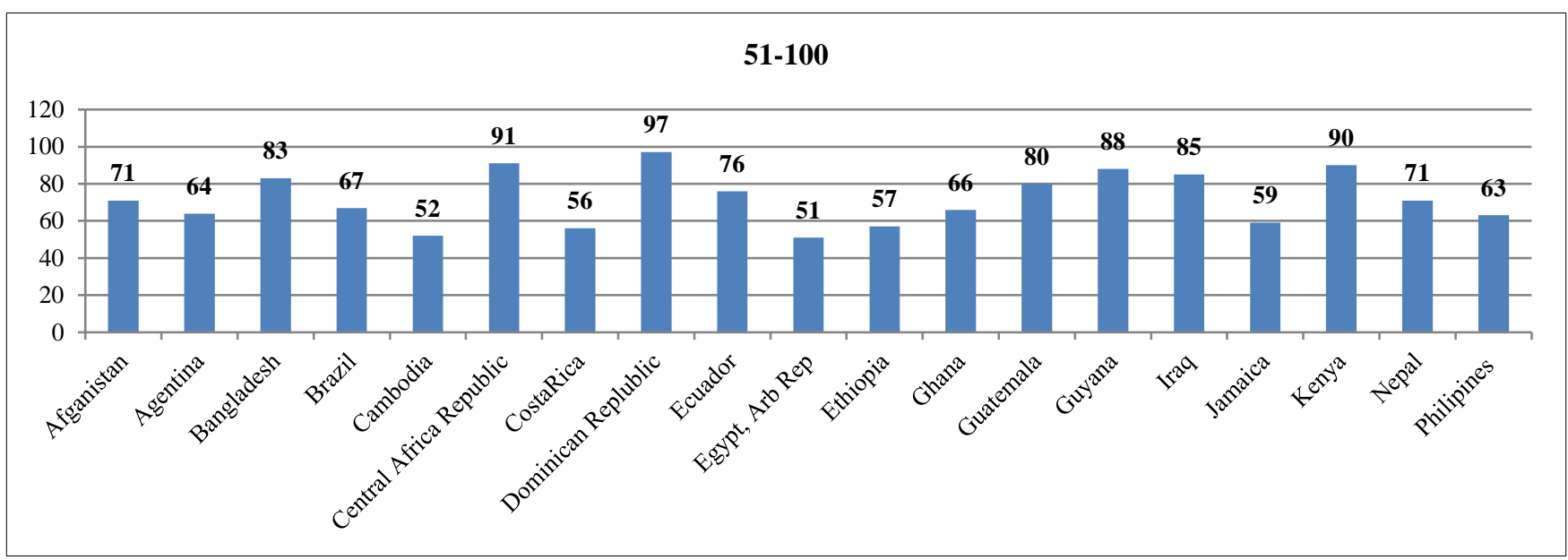

Figure 2: Global adolescent fertility rate (births per 1,000 women ages 15-19) (50-100).

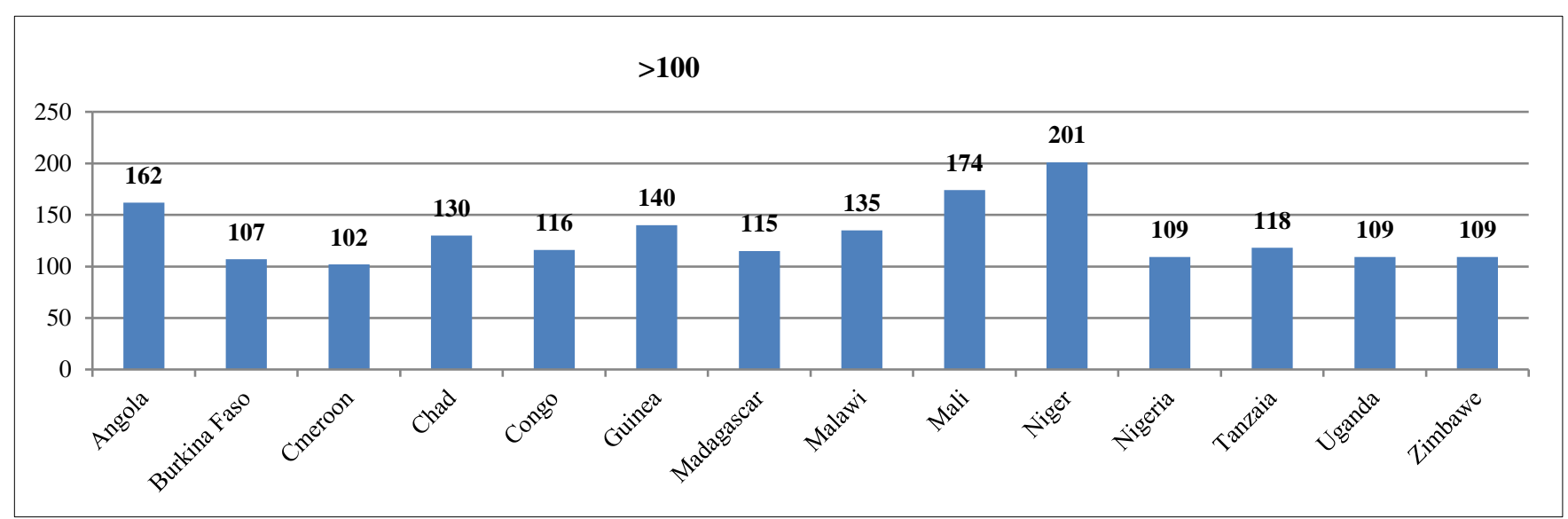

Figure 3: Global adolescent fertility rate (births per 1,000 women ages 15-19) (>100). 
At the time of survey (NHFS-4) it was observed that as high as $40.7 \%$ of women aged 20-24 years were married before age 18 years and $18.3 \%$ of women aged 15-19 years were already mothers or pregnant in West Bengal, lowest in Punjab i.e. $7.6 \%$ and $2.6 \%$ respectively. In the analysis of urban and rural area it was observed that rural adolescent pregnancies were more in comparison to urban in all state except Goa (Figure 4).

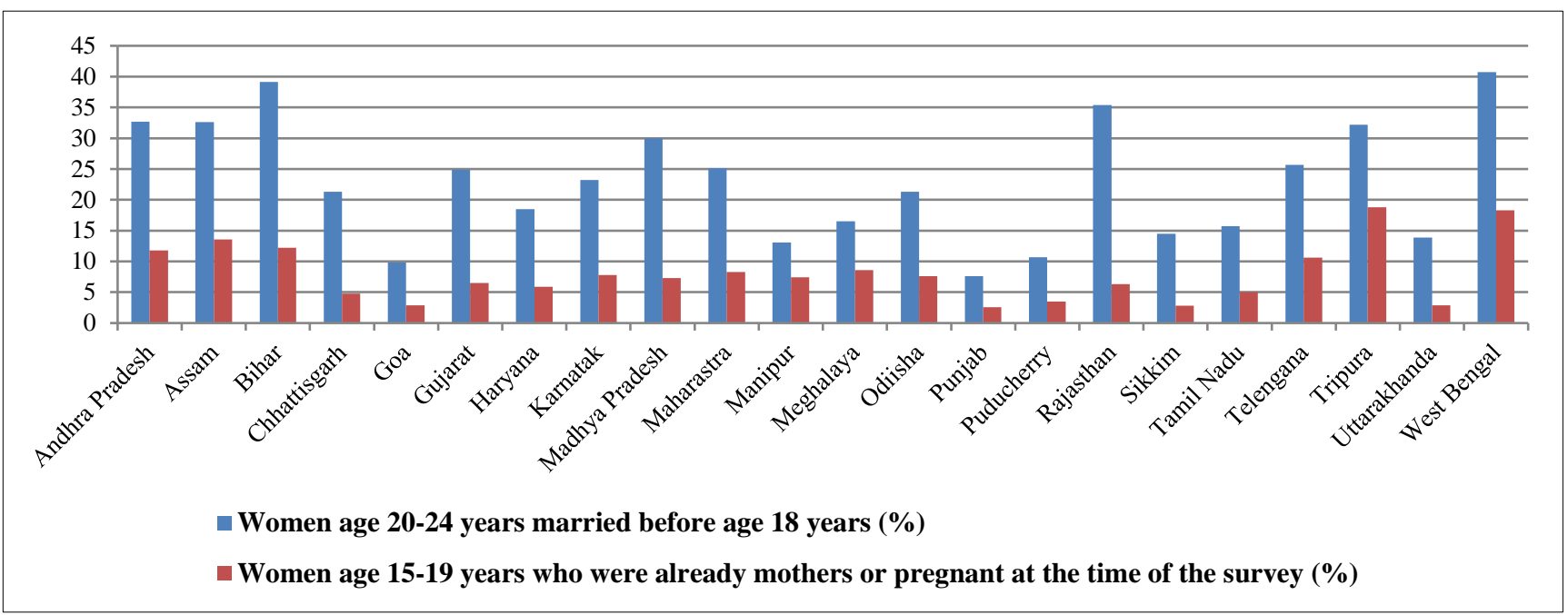

Figure 4: Incidence of marriage and pregnancy in adolescent (NHFS-4).

\section{Challenges related to adolescent pregnancy}

The challenges faced due to adolescent pregnancy are: 3.2 million unsafe abortions occur among adolescents each year; 20,000 girls give birth every day; 70,000 adolescent die due to pregnancy and childbirth related complications; adolescent mothers missed educational and other opportunities; it perpetuates poverty, basic human rights denied and girls potential remains unfulfilled.

Table 1: The consequences of adolescent pregnancy.

\begin{tabular}{|llll|}
\hline Maternal & Intrapartum & Postpartum & Neonatal \\
\hline Antenatal & & - Anemia & \\
- Abortion & - Preterm labor & - Nutrition deficiency & - Prematurity \\
- Anemia & - Prolonged labor & - Puerperal sepsis & - Small for gestational age \\
- Hypertensive disorder of & - Birth injuries & - Contraception & \\
pregnancy & & - Psychological Problem & \\
- STIs/HIV & & & \\
\hline
\end{tabular}

\section{Factors contributing to adolescent pregnancy}

The factors which place teens at increased risk of adolescent pregnancy are: residing in disorganized/dangerous neighborhoods, lower SES family, living with a single parent, having older sexually active siblings or pregnant/parenting teenage sisters, and being a victim of sexual abuse. All these factors place teens at an elevated risk of adolescent pregnancy. Several biological factors (timing of pubertal development, hormone levels, and genes) are also related to adolescent pregnancy risk because of their association with adolescent sexual intercourse. ${ }^{5}$ Research findings are most consistent with the fact that parent/child closeness or connectedness, parental supervision or regulation of children's activities, and parents value against teen intercourse (or unprotected intercourse) decrease the risk of adolescent pregnancy. ${ }^{6}$

\section{Social pressure}

Although the legal age of marriage is 18 years, early marriage in India is not uncommon. In many societies as 
soon as the girls attain menarche they are under pressure to marry and bear children early as they may be unable to refuse sex.

\section{Low education}

Birth rates among women with low education are higher than for those with secondary or tertiary education.

\section{Knowledge of contraception}

Due to low education, adolescents do not know how to avoid becoming pregnant, they are unable to obtain contraceptives even where contraceptives are widely available and sexually active adolescents are less likely to use contraceptives than adults.

In Latin America, Europe and Asia only 42-68\% of adolescents who are married or in partnerships use contraceptives. In Africa the rate ranges from 3-49\%.

\section{Effects on the adolescent mother}

\section{Abortion}

This may be spontaneous or induced. Sexual activity during adolescence can lead to unwanted pregnancy which in turn can result in serious maternal complications in the form of septic abortion. In the long term it may lead to pelvic inflammatory disease and subsequent infertility.

\section{Anemia}

Anemia in pregnancy per se is not caused by young age, poor eating habits and infrequent antenatal care make them vulnerable for it. Prevalence of anemia in adolescent girl is $41.1 \%$. $^{7}$

Leading cause of adolescent anemia in India is iron deficiency, other causes could be hookworm infestation, infectious diseases such as tuberculosis, vitamin-A deficiency and hemoglobinopathies. It is significantly high in adolescent who become pregnant i.e. $62.9 \% .^{8}$

\section{Developmental issue due to nutritional requirement}

Nutritional requirement for an adolescent mother is more in comparison to adult mother as the former's body is still developing. Over and above they need to fulfill the demand due to pregnancy. So, failure to meet the demand affects the growth of both mother and infant.

\section{Hypertensive disorder of pregnancy}

In India incidence of eclampsia is $10 \% .{ }^{9}$ The incidence of preeclampsia increase by two-fold in pregnant adolescent in comparison to women between $30-34$ years. ${ }^{10}$

\section{Sexually transmitted disease}

1 in 4 adolescent females who are sexually active, have STD, such as chlamydia or human papillomavirus (HPV). ${ }^{11}$ Sexually active adolescents are at higher risk of acquiring STDs due to a combination of behavioral, biological, and cultural reasons. For some STDs, such as chlamydia, adolescent females may have increased susceptibility to infection because of increased cervical ectopy as these cells are more susceptible to infection. The higher prevalence of STDs among adolescents may also reflect multiple barriers to accessing quality STD prevention and management services.

\section{Preterm labor}

Risk of preterm birth in pregnant adolescents is higher than adult pregnancy, it is $25 \%$ among white adolescents and $39 \%$ among black adolescent. ${ }^{12}$ The reasons are no or late antenatal care, social deprivation, physical abuse, smoke and substance abuse.

\section{Prolonged labor}

The incidence of prolonged labor is 4\% among 12-16 years old girls compared to $0.3 \%$ in women of $20-29$ years. This may be directly due to fetopelvic disproportion.

\section{Birth injuries}

Due to small capacity of genital organ and increased operative deliveries laceration of genital tract leading to hemorrhage is more common in adolescent mother. In this mater increased incidence of cervical laceration and perineal laceration was noted by Hassan et al and Briggs et al respectively. ${ }^{13,14}$

\section{Psychological problem}

Adolescent mothers experience significantly higher rates of depression, both prenatally and postpartum, than adult mothers and their non-pregnant peers. ${ }^{15}$ The researchers found that girls ranging from 15 to 19 experienced postpartum depression at a rate that was twice as high as women aged 25 and older. ${ }^{16}$ Among adolescent mothers, rates of depression are estimated to be between $16 \%$ and $44 \%$. In contrast, the lifetime prevalence of major depression among non-pregnant adolescents and adult women is between 5\% and 20\%. ${ }^{17}$ Approximately $19 \%$ of all 15- to 19-year-olds report having thoughts of suicide, and $\sim 9 \%$ have made a suicide attempt. ${ }^{18}$ Teen mothers are also at risk for developing symptoms of posttraumatic stress disorder, mainly because of their high risk for community and interpersonal violence exposure including physical attacks by a partner, neglect and abuse by a parent. ${ }^{19}$ Adolescent mothers are exposed to multiple psychological problems varying from low self-esteem to severe depression. This is due to poverty, domestic violence, dysfunctional family relationships, underlying 
psychiatric disorder. ${ }^{20}$ Pregnant adolescents are more likely to smoke and use alcohol than are older women in developed country, which can cause many problems for the child and after birth.

The teenage mother often discontinues her education and is locked into a poverty syndrome. Teenage marriages break up faster than other marriages and have the highest divorce rate of all.

A survey done in Japan shows that women who have their first baby before age 18 have $1 / 3$ less chance of breast cancer than women who have their 1st baby after age 35 . If all births to women under 18 were eliminated, the population would be $5 \%$ smaller in 50 years than if these rates remain constant. If all teenage births were eliminated the net reproduction rate would be reduced from 1.16 to just over the stationary value of $1.00 .^{21}$

\section{Effect on neonate, infant and children}

\section{Congenital malformation}

It has been noticed that pregnancy in young age is associated with increased CNS, gastrointestinal and musculo-skeletal system, most common being CNS anomalies other than anencephaly, spina bifida/meningocele, hydrocephalus and microcephalus. The gastrointestinal anomalies attributed to omphalocele /gastroschisis; musculoskeletal/ integumental anomalies mainly attributed to cleft lip/palate and polydactyly/syndactyly/adactyly. The exact reason not known but some correlations are registered, between body mass index before pregnancy, folic acid and other multivitamin requirement before and during pregnancy. $^{22,23}$

\section{Low birth weight}

Mukhopadhyay et al in their study revealed that the teenage mothers had a higher proportion $(27.7 \%)$ of preterm deliveries compared to $13.1 \%$ in the adult mothers and had low-birthweight babies (38.9\% vs $30.4 \%$ respectively). ${ }^{24}$ It is associated with significant proportion weighing $<2.5 \mathrm{~kg}$, higher incidence of prematurity, major congenital defects and a perinatal mortality of 18.7 per 1,000 births. ${ }^{25}$

\section{Neonatal morbidities and mortality}

Morbidities like perinatal asphyxia, jaundice and respiratory distress syndrome are more in adolescent pregnancy than adult pregnancy i.e. $(11.7 \%$ vs $1.9 \%)$, $(5.7 \%$ vs $1.2 \%)$ and $(1.9 \%$ vs $0.3 \%)$ respectively. Teenage pregnancy is also associated with higher fetal $(1.9 \%$ vs $0.3 \%)$ and neonatal mortality $(3.8 \%$ vs $0.5 \%) .{ }^{26}$ Still birth rate was also significantly higher in teenage deliveries $\left(5.1 \%\right.$ vs $0.9 \%$ respectively). ${ }^{27}$ Besides, children born to teenage mothers are more likely to experience social, emotional, and other problems like malnutrition, low cognitive and social stimulation leading to poor academic achievement. They also at increased risk for abuse and neglect. Boys are $13 \%$ more likely to be incarcerated and girls are $22 \%$ more likely to be teen age mother. ${ }^{28}$

\section{Prevention of adolescent pregnancy and its complications}

If all births to women under 18 were eliminated, the population would be $5 \%$ smaller in 50 years than if these rates remain constant and the net reproduction rate would be reduced from 1.16 to just over the stationary value of $1.00 .^{21}$ As per WHO Guidelines on preventing early pregnancy and poor reproductive outcomes among adolescents in developing countries (2011) following recommendations have been made with six key objectives. ${ }^{29}$ Intervention must aim to

\section{A. Prevent early pregnancy}

\section{Reduce marriage before age 18}

- What can policy-makers do?

i. Prohibit early marriage.

- What can individuals, families and communities do?

i. Keep girls in school.

ii. Influence cultural norms that support early marriage.

- What can researchers do?

i. Build evidence on the types of interventions that can result in the formulation of laws and policies (e.g., public advocacy).

ii. To find out economic incentives and livelihood programs that can delay the age of marriage.

iii. To assess the impact of education and school enrolment

iv. Assess the feasibility of existing interventions to inform and empower adolescent girls, their families and their communities.

Create understanding and support to reduce pregnancy before age 20.

- What can policy-makers do?

i. Support pregnancy prevention programs among adolescents.

- What can individuals, families and communities do?

i. Educate girls and boys about sexuality.

ii. Build community support for preventing early pregnancy.

- What can researchers do?

i. Build evidence on the effect of interventions to prevent early pregnancy, including those that increase employment, school retention, education availability, and social supports.

ii. Conduct research across socio-cultural contexts to identify feasible and scalable interventions to reduce early pregnancy among adolescents.

Increase use of contraception by adolescents at risk of unintended pregnancy

- What can policy-makers do?

i. Legislate access to contraceptive information and services. 
ii. Reduce the cost of contraceptives to adolescents

- What can individuals, families and communities do?

i. Educate adolescents about contraceptive use.

ii. Build community support for contraceptive provision to adolescents.

iii. Enable adolescents to obtain contraceptive services

- What can researchers do?

i. Build evidence on the effectiveness of different interventions to increase contraceptive.

ii. Understand how gender norms affect contraceptive use.

Reduce coerced sex among adolescents

- What can policy-makers do?

i. Prohibit coerced sex.

- What can individuals, families and communities do?

i. Empower girls to resist coerced sex.

ii. Influence social norms that condone coerced sex.

iii. Engage men and boys to critically assess norms and practices.

- What can researchers do?

i. Build evidence on the effectiveness of laws and policies aimed at preventing sexual coercion.

ii. Assess how laws and policies are formulated, enforced and monitored in order to understand how best to prevent the coercion of adolescent girls

\section{B. Prevent adverse reproductive outcome.}

\section{Reduce unsafe abortion among adolescents}

- What can policy-makers do?

i. Enable access to safe abortion and post-abortion services.

- What can individuals, families and communities do?

i. Inform adolescents about safe abortion services.

ii. Increase community awareness of the dangers of unsafe abortion.

iii. Identify and remove barriers to safe abortion services.

- What can researchers do?

i. Identify and assess interventions that reduce barriers to the provision of safe and legal abortion services in multiple socio-cultural contexts.

ii. Build evidence on the impact of laws and policies that enable adolescents to obtain safe abortion and post-abortion services.

Increase use of skilled antenatal, childbirth and postnatal care among adolescents

- What can policy-makers do?

i. Expand access to skilled antenatal, childbirth and postnatal care.

ii. Expand access to emergency obstetric care

- What can health systems do?

i. Ensure that adolescents, their families and communities are well prepared for birth and birth-related emergencies. ii. Be sensitive and responsive to the needs of young mothers and mothers-to-be.

- What can researchers do?

i. To identify and eliminate barriers that prevent the access to and use of skilled antenatal, childbirth and postnatal care

ii. Develop and evaluate interventions that inform adolescents and stakeholders about the importance of skilled antenatal and childbirth care.

iii. Identify interventions to tailor the way in which antenatal, childbirth and postnatal services are provided to adolescents;

\section{CONCLUSION}

Teenage pregnancy is associated with a significantly higher risk of PIH, PET, eclampsia, premature onset of labor, premature delivery and fetal deaths. Increased neonatal morbidity and mortality are also seen in babies delivered to teenage mothers. Over the past 25 years adolescent pregnancy and birth rate shows a decreasing trend across the industrialized world. The reasons for this general trend are increased importance of education, easy access to contraception, implementation of policy on marriageable age, goals other than motherhood and family formation for young women. Economic, social development and progress of any country depend on the healthy adolescent size. So, healthier is the adolescent, healthier will be the future generation and nation. Hence adolescents require our special attention.

Funding: No funding sources

Conflict of interest: None declared

Ethical approval: Not required

\section{REFERENCES}

1. http://www.who.int/maternal_child_adolescent/topic s/maternal/adolescent_pregnancy

2. http://www.unfpa.org/adolescent-pregnancy

3. WHO Fact sheet No.364 May 2012.

4. http://www.indiatomorrow.net the-epidemic-ofteenage-pregnancy-an-Indian-tragedy. Retrieved 2 September 2015.

5. Dawan, Himanshi (28 November 2008). Teen pregnancies higher in India than even UK, US. The Economic times. Retrieved 2 May 2013.

6. Miller BC, Benson B, Galbraith KA. Family relationships and adolescent pregnancy risk: A research synthesis. Dev Rev. 2001 Mar 1;21(1):1-38.

7. Biradar SS, Biradar SP, Alatagi AC, WantamutteAS, Malur PR. Prevalence of anemia among adolescent girl: a one year cross sectional study. J Clin Diagnostic Res. 2012;1-6.

8. Banarjee B, Pandey GK, DuttaD, Sengupta B, Mondal M, Deb S. Teenage pregnancy: A socially inflicted health hazard. Ind $\mathrm{J}$ Community Med. 2009;34:227-31. 
9. Aznar R, Bennet AE. Pregnancy in adolescent girl. Am J Obstet Gynecol.1961;81:934

10. Scholl TO, Hediger ML, Belsky DH. Perinatal care and maternal health during adolescent pregnancy: a review and meta-analysis. $\mathrm{J}$ Adolesc Health. 1944;15(6):444-56.

11. Forhan SE, Gottlieb SL, Sternberg MR, Xu F, Datta SD, McQuillan GM, et al. Prevalence of sexually transmitted infections among female adolescents aged 14 to 19 in the United States. Pediatrics. 2009;124(6):1505-12.

12. Leland NL, Petersen DJ, Braddock M, Alexander GR. Variations in pregnancy outcome by race among 10-14 years old mothers in US. Public Health Report. 1995;110:53-8.

13. Hassan H, Fredrick H Falls. The young primipara. Am J Obstet Gynecol. 1964;84:256-68

14. Briggs RM, Reginald R, Herren W. Pregnancy in young adolescent. Am J Obstet Gynecol. 1964;84:436-8.

15. Hodgkinson SC, Colantuoni E, Roberts D, BergCross L, Belcher HM. Depressive symptoms and birth outcomes among pregnant teenagers. J Pediatr Adolesc Gynecol. 2010; 23(1):16-22.

16. Dawn K, Maureen H, Deshayne F, Beverley C. Comparison of adolescent, young adult, and adult women's maternity experiences and practices. Pediatrics. 2012;129: 5.

17. Kessler RC. Epidemiology of women and depression. J Affect Disord. 2003;74(1):5-13.

18. Dopheide JA. Recognizing and treating depression in children and adolescents. Am J Health Syst Pharm. 2006;63(3):233-243.

19. Kennedy AC, Bennett L. Urban adolescent mothers exposed to community, family, and partner violence: is cumulative violence exposure a barrier to school performance and participation? J Interpers Violence. 2006;21(6):750-773.

20. Dahmen B, Firk C, Konrad K Herpertz-Dahlmann BZ. Kinder Adolescent parenting - developmental risks for the mother-child dyad. Jugendpsychiatr Psychother.2013 Nov;41(6):407-17.

21. Menken J. The health and social consequences of teenage childbearing. Fam Plann Perspect. 1972;4(3):45-53.

22. Sirakov M. Congenital malformations in teenage pregnancy. Akush Ginekol (Sofiia). 2012;51(4):3540

23. Xi-K C, Shi W W,Nathalie F, Qiuying Y,Mark C. W.Teenage pregnancy and congenital anomalies: which system is vulnerable? Hum. Reprod. 2007;22 (6):1730-5.

24. Mukhopadhyay P, Chaudhuri RN, Paul B. Hospitalbased perinatal outcomes and complications in teenage pregnancy in India. J Health Popul Nutr. 2010 Oct;28 (5):494-500.

25. Gavrielle K, Jia YL, Anita SK, Le YL. Adverse effects of young maternal age on neonatal outcomes. Singapore Med J. 2015;56(3):157-163.

26. Kumar A, Singh T, Basu S, Pandey S, Bhargava V. Outcome of teenage pregnancy. Indian $\mathrm{J}$ Pediatr. 2007 Oct;74(10):927-31.

27. Azevedo WF, Diniz MB, Fonseca ES, Azevedo LM, Evangelista CB.Complications in adolescent pregnancy: systematic review of the literature Einstein (Sao Paulo). 2015;13(4):618-26.

28. Teen Pregnancy. Available at http://www.healthcommunities.com/teenpregnancy/children/risks-to-baby-in-teen-pregnancy

29. Preventing early pregnancy and poorreproductive outcomes among adolescents in developing countries: what the evidence says. Available ta Who.int/iris/bitstream/10665/70813/1/WHO_FWC_ MCA_12_02_ebg.pdf.

Cite this article as: Ghose S, John LB. Adolescent pregnancy: an overview. Int J Reprod Contracept Obstet Gynecol 2017;6:4197-4203. 